\title{
Estratégia de produção de uma empresa fabricante de peças para automóveis
}

Daniel França Lazarin danielflazarin@ufu.br Universidade Federal de Uberlândia(UFU), Ituiutaba, Minas Gerais, Brasil

\section{Edemilson Nogueira} edn@dep.ufscar.br

\author{
RESUMO
}

O desenvolvimento tecnológico intenso nas últimas décadas, proporcionado principalmente pela microeletrônica, a intensificação do comércio entre os países, o fornecimento global utilizado por grandes corporações, entre outros aspectos, têm tornado a competição nos diferentes mercados cada vez mais acirrada. Nesse cenário, a abordagem estratégica para a gestão da produção é fundamental para as empresas manterem-se competitivas. Este estudo teve como objetivo identificar e analisar a estratégia de produção de uma empresa fabricante de peças para automóveis. O método de pesquisa utilizado foi o estudo de caso, realizado por meio de entrevistas, observação direta e consulta a fontes de dados secundárias. Como resultado conseguiu-se verificar: as prioridades competitivas destacadas pela empresa, sendo qualidade e entrega consideradas as mais importantes; as ações realizadas nas diversas áreas de decisão estruturais e infra-estruturais; e as ações nas áreas de decisão que contribuem para o alcance das prioridades competitivas da fábrica estudada. Para a melhoria da prioridade qualidade, destaca-se o trabalho realizado junto a seus fornecedores como a exigência de certificação de qualidade ISO 9001:2000; premiação aos fornecedores que mais se destacam em suas atividades; utilização de ferramentas da qualidade etc. Já para a prioridade entrega, as ações voltadas para desenvolvimento do PCP (planejamento e controle da produção), entre outras, têm contribuído de forma importante para o desempenho exigido na prioridade em questão.
\end{abstract}

PALAVRAS-CHAVE: Estratégia de Produção. Prioridades Competitivas. Áreas de Decisão Estruturais. Áreas de Decisão Infra-Estruturais. Indústria do Setor de Autopeças. 


\section{INTRODUÇÃO}

A essência de uma estratégia é a de alcançar uma vantagem competitiva de longo prazo perante os concorrentes em cada negócio que a organização participa (FINE; HAX, 1985). Diante disso, a definição de estratégia e seu consequente planejamento passaram a fazer parte das necessidades básicas das organizações. Existe na literatura um grande número de definições para o termo estratégia que variam em termos de amplitude e abrangência.

A estratégia é um padrão global de decisões e ações que posicionam a organização em seu ambiente e têm o objetivo de fazê-la atingir seus objetivos de longo prazo (SLACK et al., 2002).

Para Ansoff e Mc Donnell (2009), a estratégia é um conjunto de regras de tomada de decisão para orientação do comportamento de uma organização.

Segundo Mintzberg et al. (2010), a estratégia, entendida como um plano, é uma ferramenta gerencial adotada para projetar o futuro, implementada por meio de um procedimento formalizado e um processo decisório articulador de resultados.

A teoria sobre estratégia de produção evoluiu significativamente nas últimas décadas, a partir de sua formulação inicial com o trabalho de Skinner (1969). Até então não se reconhecia devidamente a importância estratégica da produção para a competitividade da empresa.

Skinner (1969) propõe em seu trabalho que, para atender às necessidades de sobrevivência, crescimento e lucro da empresa, a produção deve ser elevada à condição de área estratégica e administrada de modo que seus recursos e competências sejam desenvolvidos e orientados para as oportunidades que surgem no mercado. Para cumprir esse papel, uma série de escolhas coerentes deve ser feita pela administração, de acordo com as prioridades competitivas da empresa, nas várias áreas de decisão da produção.

Nesse sentido, este estudo tem por objetivo analisar a estratégia de produção de uma empresa fabricante de peças para automóveis. Mais precisamente busca-se responder três questões:

Questão 1-) Quais são as prioridades competitivas destacadas pela empresa com o intuito de satisfazer seu mercado consumidor?

Questão 2-) Quais são as ações realizadas nas áreas de decisão estruturais e infraestruturais?

Questão 3-) Destas ações nas áreas de decisão, quais contribuem para o alcance das prioridades competitivas destacadas pela empresa?

\section{REFERENCIAL TEÓRICO}

Esta seção tem por objetivo apresentar uma breve revisão teórica a respeito do tema desta pesquisa. Inicialmente discorre-se sobre os tipos de estratégias existentes para posteriormente apresentar os conceitos e o conteúdo da estratégia de produção. 


\section{ESTRATÉGIA}

Porter (1996) argumenta a favor da importância da estratégia para o sucesso da empresa e ressalta que ela (estratégia) não deve ser confundida com a eficácia operacional. Tanto a eficácia operacional como a estratégia são essenciais para o desenvolvimento superior, que é o objetivo primordial de todas as empresas, mas uma e outra atuam de formas muito diferentes. Segundo ainda este mesmo autor, a eficácia operacional significa o desempenho de atividades melhor do que os rivais. Diz respeito a quaisquer práticas pelas quais a empresa utiliza melhor os insumos, como por exemplo, o desenvolvimento de produtos com maior rapidez. Em contraste, o posicionamento estratégico significa desempenhar atividades diferentes das exercidas pelos rivais ou desempenhar as atividades de maneira diferente. A estratégia se alicerça na exclusividade das atividades.

Nesta pesquisa, a estratégia top-down é enfatizada e ela é subdividida em três níveis principais, a corporativa, a de negócios e a funcional (WHEELWRIGHT, 1984).

Um melhor entendimento pode ser obtido observando a Figura 1:

Figura 1 - Hierarquia de estratégias

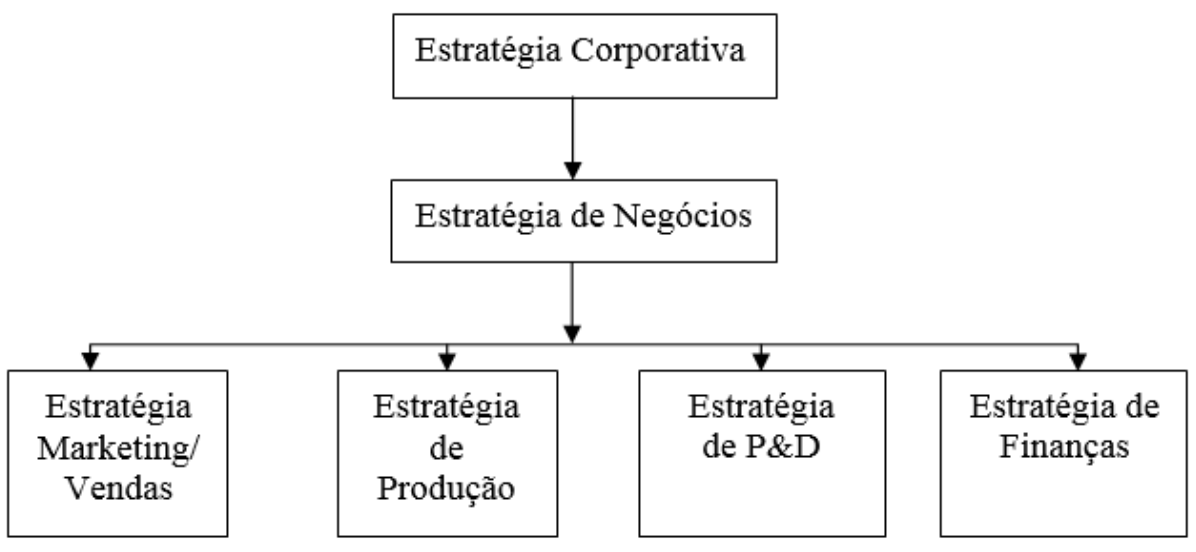

Fonte: Wheelwright (1984)

O primeiro nível hierárquico corresponde à estratégia corporativa, também conhecida como estratégia global; é a mais abrangente delas, uma vez que diz respeito a toda corporação. Segundo Wheelwright (1984), a estratégia corporativa especifica duas áreas de total interesse para a corporação: a definição dos negócios nas quais a corporação irá participar e a aquisição e alocação de recursos corporativos para cada um desses negócios.

A estratégia corporativa é, segundo Mintzberg e Quinn (1991), "o padrão de decisões em uma companhia que determina e revela seus objetivos, propósitos ou metas, gera as principais políticas para atingir tais objetivos, e define a gama de negócios em que a companhia atuará, o tipo de organização econômica e humana que ela é ou almeja ser, e a natureza das contribuições econômicas e não-econômicas que ela planeja fazer a seus acionistas, empregados, consumidores e comunidades". 
Nesse sentido, a organização no nível corporativo da estratégia toma decisões que a compromete no longo prazo, uma vez que estão envolvidas questões como: negócios que participará, a origem dos recursos necessários para financiamento das atividades e a seqüência de investimentos a serem realizados para se atingir determinado fim.

O segundo nível é o da estratégia de negócios. Uma unidade de negócios pode ser descrita como uma empresa, uma divisão ou uma fábrica. Chamada também de estratégia competitiva, este nível especifica em que bases a unidade de negócio irá alcançar e manter uma vantagem competitiva (HAYES; WHEELWHRIGHT, 1984). Ao especificar uma estratégia para uma linha de produto, ou segmento de mercado, permite-se foco nos esforços para atingir melhores resultados de desempenho e assim galgar uma vantagem competitiva naqueles nichos.

Porter (1986) sugere a análise do contexto externo à empresa para entender a dinâmica de seu mercado e assim, buscar uma posição que a permita obter uma vantagem competitiva sustentada. Tal autor propôs um modelo de análise estrutural da indústria a partir de cinco forças que dirigem a concorrência, conforme mostra a Figura 2.

(a) Entrada de novos concorrentes;

(b) Ameaça de produtos substitutos;

(c) Poder de barganha dos compradores;

(d) Poder de negociação dos fornecedores; e

(e) Rivalidade entre os atuais concorrentes.

Figura 2 - Forças competitivas de uma indústria

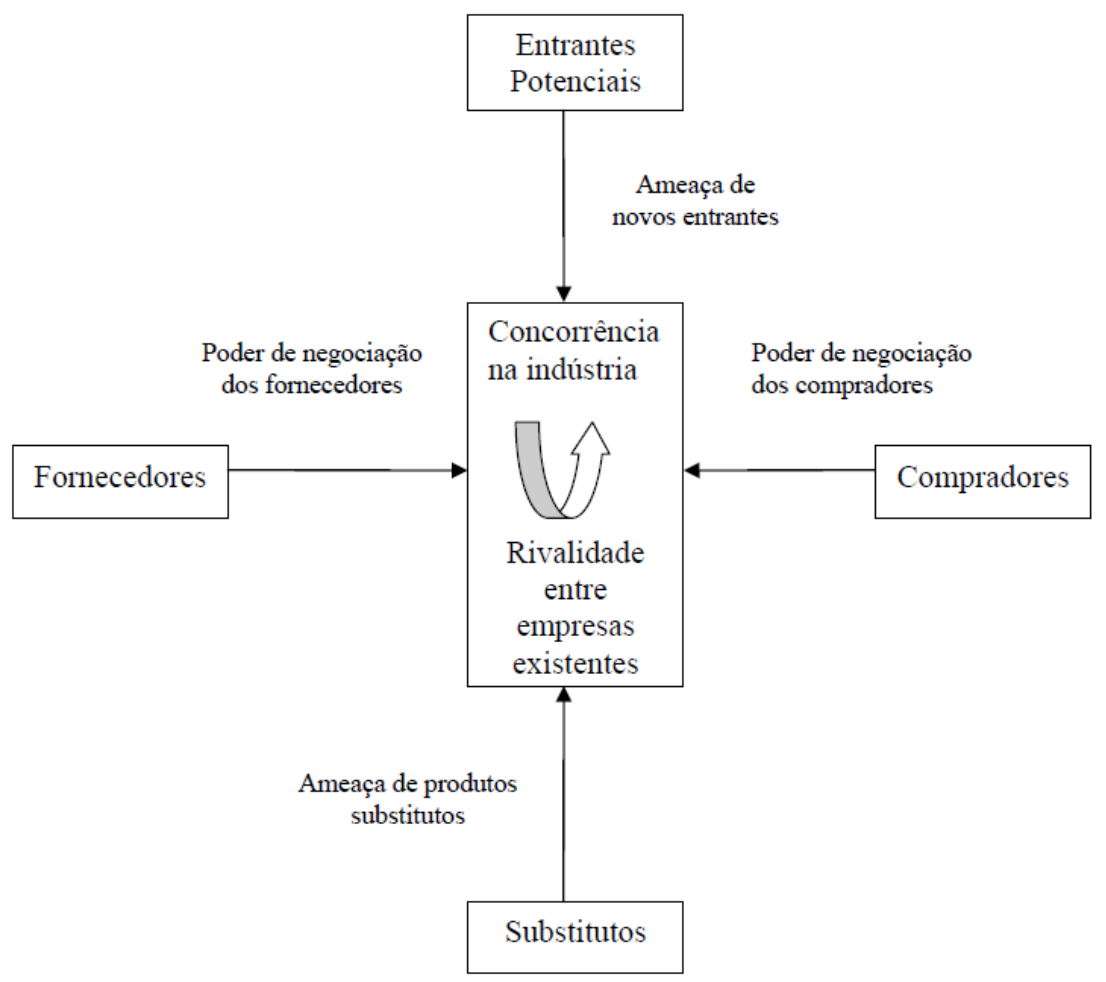

Fonte: Porter (1986) 
Essas cinco forças dizem respeito às características inerentes a cada setor industrial, de forma que a empresa, ao identificar seus pontos fortes e críticos em relação a elas, seja capaz de elaborar uma estratégia que a posicione da melhor maneira perante seus concorrentes. A intensidade da competição varia de acordo com o setor industrial, bem como com os segmentos existentes dentro deste setor. Por exemplo, o poder de negociação dos fornecedores da indústria automobilística não é o mesmo dos fornecedores da indústria de revestimentos cerâmicos ou de calçados, assim como o poder de uma grande empresa de eletroeletrônicos junto ao varejo é muito diferente do poder que uma pequena confecção de roupas possui diante dos revendedores (NOGUEIRA, 2002).

Porter (1986) também considera que, "ao enfrentar as cinco forças competitivas, existem três abordagens estratégicas genéricas, potencialmente bem sucedidas, para superar as outras empresas em uma indústria", são elas: liderança no custo total; diferenciação; e foco.

A primeira visa obter vantagens competitivas pela oferta de produtos e serviços a um preço mais baixo que os concorrentes. A segunda consiste em diferenciar o produto ou serviço oferecido pelas empresas, criando algo que seja único no âmbito da indústria. Já a terceira estratégia tem como objetivo focar um grupo comprador, um segmento da linha de produtos ou um mercado geográfico.

O terceiro nível corresponde às estratégias funcionais, cujo objetivo é dar suporte às vantagens competitivas desejadas pela unidade de negócio e especificar como as unidades irão implementar programas de ações integrados e compatíveis (GUPTA; LONIAL, 1998). As estratégias funcionais mais citadas são: estratégia de marketing, tecnológica, de produção, finanças, de desenvolvimento de produtos, compras, recursos humanos, etc.

Da mesma forma que deve existir uma perfeita concordância entre a estratégia da corporação e a estratégia de negócios, o mesmo deve acontecer em relação às estratégias funcionais (PIRES, 1994).

A garantia de alcançar os objetivos propostos pela estratégia corporativa, só existe se houver uma perfeita sintonia no seu desdobramento para os demais níveis hierárquicos.

A estratégia de produção, segundo Gupta e Lonial (1998), pertence ao terceiro nível hierárquico de estratégias, junto às demais estratégias funcionais (ver Figura 1); e de acordo com Swamidass (1986), ela implica no desenvolvimento das capacidades da produção em total alinhamento com os objetivos e estratégias da empresa.

Neste artigo, o foco é a estratégia de produção, tendo em vista que a função produção é o cerne de uma organização, como justifica Slack et al. (2002): "ela (função produção) produz os bens e serviços que são a razão da existência da organização".

\section{ESTRATÉGIA DE PRODUÇÃO}

A argumentação inicial de Skinner, a respeito da importância da função produção para a estratégia da empresa, tem conduzido a várias definições sobre 
o conceito de estratégia de produção, cada uma enfocando um aspecto particular da gestão da produção.

Para Mills et al. (1995), estratégia de produção é o uso efetivo de forças da produção como uma arma competitiva para se atingir os objetivos do negócio e as metas corporativas.

Estratégia de produção é um conjunto de metas, políticas e restrições auto impostas que descrevem como a organização planeja dirigir e desenvolver todos os recursos investidos na produção para melhor cumprir (e possivelmente redefinir) sua missão (HAYES et al., 2008).

A estratégia de produção deve buscar a melhoria da capacidade produtiva, a utilização racional dos recursos e o desenvolvimento das prioridades competitivas para se tornar um fator determinante para a vantagem competitiva (GÖLEÇ, 2015).

De acordo com Lara (2013), a função produção foi por muitos anos restringida ao nível de chão de fábrica, sem se levar em consideração o posicionamento estratégico que possui na organização. Ainda segundo Lara (2013), no entanto, diversos autores (HAYES E WHEELWRIGHT, 1984; HILL, 1989; HAYES e PISANO, 1994; VOSS, 1995; WARD e DURAY, 2000; DAVIS et al., 2001; SUN e HONG, 2002; AMOAKO-GYAMPAH e ACQUAAH, 2008; HAYES et al., 2008; SANTOS et al., 2011) apontam a importância da estratégia de produção no contexto organizacional. Acredita-se que ela deva dar suporte à estratégia competitiva ou de negócio, oferecendo uma contribuição importante para a sobrevivência de uma organização.

A caracterização da estratégia de produção passa por dois conjuntos de questões, o conteúdo e o processo. Para Slack et al. (2002), o conteúdo da estratégia de produção envolve decisões e ações específicas que estabelecem o papel, os objetivos e as atividades da produção. Já o processo da estratégia da produção é o método usado para produzir as decisões específicas do conteúdo. Cabe destacar que para este trabalho foram analisados somente os elementos do conteúdo da estratégia de produção da empresa estudada.

O conteúdo da estratégia de produção compreende as prioridades competitivas da produção e o conjunto das áreas de decisão (estruturais e infraestruturais). De acordo com Díaz-Garrido et al. (2011), as prioridades competitivas se referem aos objetivos que as empresas devem perseguir de modo a reforçar suas vantagens competitivas. Elas devem compor um conjunto consistente de prioridades que orientarão todas as decisões, os programas e as ações implementados nas áreas de decisão estruturais e infra-estruturais.

As prioridades competitivas foram inicialmente identificadas por Skinner (1969) como sendo: produtividade, serviço, qualidade e retorno sobre o investimento. Em trabalhos subsequentes, outros autores apresentaram diferentes combinações de prioridades como ilustra o Quadro 1. 
Quadro 1 - Combinações de prioridades competitvas abordadas na literatura

\begin{tabular}{|l|l|}
\hline Autor (es) & Prioridades competitivas \\
\hline $\begin{array}{l}\text { Hayes e Wheelwright } \\
(1984)\end{array}$ & Custo, qualidade, confiabilidade e flexibilidade \\
\hline Garvin (1993) & Custo, qualidade, flexibilidade, entrega e serviço \\
\hline Ritzman e Krajewski (2003) & Custo, qualidade, flexibilidade, entrega e serviço \\
\hline Nair e Boulton (2008) & Custo, qualidade, entrega, flexibilidade e inovação \\
\hline $\begin{array}{l}\text { Amoako-Gyampah e } \\
\text { Acquaah (2008) }\end{array}$ & Custo, entrega, flexibilidade e qualidade \\
\hline Calife et al. (2010) & Custo, entrega, flexibilidade, qualidade e serviço \\
\hline Kroes e Ghosh (2010) & Custo, qualidade, entrega, flexibilidade e inovação \\
\hline $\begin{array}{l}\text { Luzzini et al. (2012) } \\
\text { Galeazzo e Klassenb } \\
\text { (2015) }\end{array}$ & $\begin{array}{l}\text { Custo, qualidade, entrega, eficiência, sustentabilidade e } \\
\text { inovaão }\end{array}$ \\
\hline
\end{tabular}

Fonte: Elaborado pelos autores

O modelo de prioridades aqui adotado será o de Garvin (1993); também utilizado por Ritzman e Krajewski (2003) e Calife et al. (2010) que apresentam as prioridades como sendo: custo, qualidade, flexibilidade, entrega e serviço.

O segundo elemento que compõe o conteúdo da estratégia de produção são as áreas de decisão. Os programas ou planos de ação serão elaborados e implementados nas diversas áreas de decisão da produção, conforme as decisões tomadas para um determinado horizonte de planejamento, para que atinjam os níveis definidos das prioridades competitivas (CALIFE et al., 2010).

Hayes e Wheelwright (1988), partindo do princípio que existe uma diversidade muito grande de decisões a serem tomadas na produção ao longo do tempo, argumentam que o agrupamento dessas decisões em categorias facilita tanto a identificação quanto a elaboração de uma estratégia de produção. E ainda classificam essas áreas de decisão em duas categorias de acordo com sua natureza: estruturais e infra-estruturais.

Para Hayes et al. (2008), as estruturais representam decisões sobre atributos físicos da organização, como a capacidade de produção (ou serviço de entrega) fornecida. Ainda, elas requerem um investimento de capital substancial e, uma vez realizadas, são difíceis de alterar ou reverter. Esse aspecto levou muitas empresas a confiar em seu processo orçamentário como o primeiro mecanismo de acesso às decisões operacionais estruturais.

Já as infra-estruturais descrevem os sistemas, políticas e práticas que determinam como os aspectos estruturais da organização devem ser gerenciados.

Em resumo, Hayes et al. (2008) propõem que as decisões sejam classificadas da seguinte forma:

- Áreas de decisão estruturais: capacidade; fornecimento e integração vertical; instalações; informação e tecnologia de processo; 
- Áreas de decisão infra-estruturais: alocação de recursos e sistemas de orçamento de capital; sistemas de recursos humanos; planejamento do trabalho e sistemas de controle; sistemas de qualidade; medição e sistemas de recompensa; sistemas de desenvolvimento de produtos e processos; organização.

Essas áreas de decisão estão estreitamente relacionadas e, portanto, o projeto do sistema de produção deve ser concebido considerando-se a necessidade de compatibilidade dessas áreas de modo que promova a sustentação da estratégia da empresa (CALIFE et al., 2010).

Alguns trabalhos recentes analisam a estratégia de produção em empresas dos setores de autopeças e metal mecânico (dentre eles, BRITO DE OLIVEIRA, 2017; GUIMARÃES et al., 2014; LARA, 2013).

No trabalho de Brito de Oliveira (2017), por meio de um estudo de natureza qualitativa, com o uso do método estudo multicasos, foram identificados e comparados os aspectos das estruturas organizacionais que favorecem o desenvolvimento de uma ou mais prioridades competitivas de empresas do setor de autopeças de uma cidade do estado de São Paulo.

Já Guimarães et al. (2014), apresentaram as características referentes ao conteúdo da estratégia de produção de quatro empresas de autopeças, além de analisar a influência das montadoras na definição desse conteúdo.

Lara (2013), por sua vez, analisou a influência exercida pelas prioridades competitivas na ocorrência de inovações em pequenas empresas do setor metal mecânico. Por se tratar de empresas de pequeno porte que possuem determinadas características específicas, o trabalho objetivou ainda analisar como essas especificidades influenciam na prática das prioridades competitivas e na ocorrência da inovação.

\section{METODOLOGIA DE PESQUISA}

Esta pesquisa tem um caráter exploratório, possui forma de abordagem qualitativa e utiliza como método o estudo de caso.

De acordo com Gil (1991), a pesquisa exploratória tem como objetivo principal o aprimoramento de ideias ou a descoberta de intuições. Dessa forma, seu planejamento deve ser bastante flexível, de modo que possibilite a consideração dos mais variados aspectos relativos ao fato estudado.

As características básicas da pesquisa qualitativa são: (i) tem o ambiente natural como fonte direta de dados e o pesquisador como instrumento fundamental; (ii) é descritiva; (iii) os pesquisadores tentam compreender os fenômenos que estão sendo estudados a partir da perspectiva dos envolvidos; e (iv) os pesquisadores utilizam o enfoque indutivo na análise dos dados (GODOY, 1995).

Martins e Theóphilo (2009) colocam que o estudo de caso trata de uma investigação empírica que pesquisa fenômenos dentro de seu contexto real, onde o pesquisador não tem controle sobre eventos e variáveis. Busca-se aprender o todo de uma situação de forma criativa, descrevendo, compreendendo e interpretando a complexidade de um caso real. 
Para Godoy (1995) o estudo de caso se caracteriza como um tipo de pesquisa cujo objeto é uma unidade que se analisa profundamente.

Dentro deste contexto, procurou-se através do estudo de caso verificar empiricamente as características gerais e aspectos relevantes da estratégia de produção de uma empresa fabricante de peças para automóveis, localizada no estado de São Paulo.

A empresa foi escolhida por ser de grande porte e apresentar uma considerável expressividade dentro do setor de autopeças. Além disso, considerou-se a facilidade de acesso e a existência de contatos junto a esta empresa, que viabilizaram a execução do trabalho de campo.

Este trabalho teve como fonte principal para coleta de dados a realização de entrevistas semi-estruturadas com o engenheiro responsável pela área de produção (operações) da empresa.

Foram realizadas um total de duas entrevistas, sendo que a primeira teve uma duração média de uma hora e meia e a segunda de três horas. Vale destacar que as entrevistas foram conduzidas a partir da utilização de roteiros previamente elaborados. Na primeira entrevista foram coletados dados referentes à caracterização da empresa como: localização, setor industrial, produtos fabricados, quantidade de modelos, mercado que atende (nacional, exportação), clientes da empresa, participação de mercado, operacionalização do sistema de produção, etc. Já na segunda foram observadas as informações associadas às prioridades competitivas de produção, e os elementos de gestão da produção relacionados às áreas de decisão estruturais e infra-estruturais da empresa.

O segundo recurso utilizado para a pesquisa foi a observação direta. Essa segunda fonte de evidência foi utilizada neste estudo para possibilitar a obtenção de informações adicionais e complementares. Assim foram realizadas visitas ao setor de produção da planta estudada.

A terceira fonte de evidência foi o exame de documentos (fontes secundárias) como boletins informativos da empresa, publicações de associações, catálogos, endereço eletrônico da companhia, etc.

O desenvolvimento do trabalho envolveu também uma revisão da literatura a respeito dos temas estratégia e estratégia de produção. De acordo com Berto e Nakano (2000), discussões conceituais a partir da literatura e revisões bibliográficas são pesquisas que se caracterizam como do tipo teóricoconceitual.

\section{A EMPRESA ESTUDADA E SUA ESTRATÉGIA DE PRODUÇÃO}

De todos os produtos fabricados pela empresa estudada, $90 \%$ são comercializados no mercado nacional e o restante (10\%) no mercado internacional, atendendo principalmente o México. A empresa direciona seus produtos para o mercado automotivo, possuindo aproximadamente $40 \%$ de participação do mercado. De acordo com o entrevistado o alto foco na qualidade é o diferencial da empresa com relação aos concorrentes, que são também na grande maioria empresas multinacionais. Os clientes da companhia são as 
montadoras de veículos e os revendedores de peças (aftermarket) que trabalham com as peças de reposição.

A produção da planta estudada opera através do sistema fazer para estoque (make to stock) e as principais etapas do processo produtivo são a usinagem e montagem dos produtos.

A seguir é apresentada a estratégia de produção da fábrica estudada por meio de suas prioridades competitivas e ações nas áreas de decisão estruturais e infra-estruturais.

\section{PRIORIDADES COMPETITIVAS}

Para o entrevistado, os fatores fundamentais para que os clientes (mercado) adquiram um produto de sua empresa são: a qualidade em primeiro lugar e a entrega em segundo. Em seguida aparecem: custo (ou preço), serviço (apoio ao cliente) e flexibilidade.

No que diz respeito à prioridade qualidade, de acordo com o entrevistado, a companhia deve apurar quais são as necessidades dos clientes e, em função destas, definir os requisitos de qualidade do produto. As montadoras de automóveis, principais clientes da empresa estudada, são muito rigorosas com relação ao padrão de qualidade dos produtos adquiridos junto a seus fornecedores que, por sua vez, necessitam ter sistemas produtivos preparados para atendê-los.

Já para a prioridade entrega, com a competição cada vez mais acirrada no mercado, é importante que os itens dos consumidores sejam entregues nas quantidades certas e na data combinada.

As demais prioridades competitivas também são valorizadas pela empresa, entretanto, têm um grau de importância menor.

Com relação ao custo, busca-se cada vez mais a redução dos custos fixos (aqueles que incidem independentemente do volume de vendas da empresa) como: salários, encargos sociais, etc; e os variáveis (aqueles que variam conforme o volume de vendas) como energia, matéria prima etc.

Para a dimensão serviço, os consumidores dão cada vez mais importância ao valor do serviço oferecido pela empresa e, segundo o entrevistado, a companhia precisa melhorar suas atividades para atender este quesito.

Já a prioridade flexibilidade é importante para atender principalmente os distribuidores de peças e serviços, que trabalham com as peças de reposição e possuem uma demanda incerta.

\section{Áreas de Decisão Estruturais e Infra-Estruturais}

As prioridades competitivas refletem as necessidades da estratégia competitiva e apontam para determinados objetivos a serem atingidos pelo sistema produtivo. Para se alcançar esses objetivos, é necessário o desenvolvimento de um padrão de ações relacionadas às áreas de decisão estruturais e infra-estruturais (ALVES FILHO et al., 2011). 
Nos Quadros 2 e 3 são apresentadas uma síntese das ações realizadas nas áreas de decisão estruturais e infra-estruturais da empresa.

Quadro 2 - Ações nas áreas estruturais

\begin{tabular}{|c|c|}
\hline Instalações & $\begin{array}{l}\text { - Quatro plantas no Brasil. } \\
\text { - No mundo possui } 117 \text { unidades, estando } \\
\text { presente em } 26 \text { países. }\end{array}$ \\
\hline Capacidade & $\begin{array}{l}\text { - Possui capacidade para produzir } 500.000 \\
\text { unidades por ano. } \\
\text { - Produz atualmente uma média de } \\
480.000 \text { unidades/ano. }\end{array}$ \\
\hline $\begin{array}{l}\text { Integração vertical/ } \\
\text { gestão de suprimentos }\end{array}$ & $\begin{array}{l}\text { - De todos os itens (componentes) que } \\
\text { compõem seus produtos, } 40 \% \text { são } \\
\text { comprados de terceiros. } \\
\text { - Possui aproximadamente } 200 \\
\text { fornecedores. } \\
\text { - Trabalha com até três fornecedores por } \\
\text { item. } \\
\text { - Fornecedores estão instalados em um } \\
\text { raio de até } 400 \text { quilômetros de distância da } \\
\text { empresa. } \\
\text { - Os critérios utilizados para a escolha do } \\
\text { fornecedor são a qualidade e a entrega } \\
\text { (itens entregues nas quantidades corretas } \\
\text { e na data prometida). } \\
\text { - A empresa prioriza trabalhar com } \\
\text { fornecedores que possuem a certificação } \\
\text { de qualidade ISO } 9001: 2000 \text {. }\end{array}$ \\
\hline
\end{tabular}

Continuação do Quadro 2 - Ações nas áreas estruturais

\section{Integração vertical/ \\ gestão de suprimentos}

- O controle de qualidade das mercadorias fornecidas por terceiros fica vinculado às normas de inspeção e controle de qualidade da empresa.

- A empresa todos os anos premia os fornecedores que mais se destacam em suas atividades e esta premiação tem como base os resultados acumulados ao longo do ano em critérios como logística, qualidade e capacidade de reação no atendimento da demanda.

- O entrevistado salienta a importância do trabalho conjunto com os fornecedores para o desenvolvimento de projetos, sobretudo com foco em inovação, qualidade, tecnologia e sustentabilidade. - A empresa faz desenvolvimento de projetos (produto/processo) em conjunto com alguns fornecedores e as mercadorias fabricadas sob marcas, desenhos e especificações fornecidos pela empresa estudada, poderá somente ser fabricada para esta e jamais para terceiros, sob nenhum pretexto. 


\begin{tabular}{|l|l|}
\hline Tecnologia de processo & - Possui atualmente $30 \%$ de máquinas \\
& automatizadas. \\
& - A empresa faz todo o projeto e \\
& desenvolvimento de um novo processo em \\
& conjunto com os fornecedores de \\
& equipamentos, dispositivos, conhecimento, \\
& entre outros. \\
& - Em termos de tecnologia de processo, a \\
& empresa se vê igual aos concorrentes. \\
\hline
\end{tabular}

Fonte: Elaborado pelos autores

Quadro 3 - Ações nas áreas infra-estruturais

\begin{tabular}{|c|c|}
\hline $\begin{array}{l}\text { Organização da } \\
\text { produção }\end{array}$ & $\begin{array}{l}\text { - A produção da planta estudada opera } \\
\text { através do sistema fazer para estoque } \\
\text { (make to stock). } \\
\text { - As principais etapas do processo } \\
\text { produtivo são a usinagem e a montagem. } \\
\text { - O arranjo físico (layout) presente é o } \\
\text { arranjo celular para todas as operações } \\
\text { (usinagem e montagem). } \\
\text { - A planta possui no chão de fábrica em } \\
\text { torno de } 350 \text { funcionários para os três } \\
\text { turnos de trabalho }\end{array}$ \\
\hline
\end{tabular}

Fonte: Elaborado pelos autores

Continuação do Quadro 3 - Ações nas áreas infra-estruturais

\begin{tabular}{|c|c|}
\hline Sistemas de recursos humanos & $\begin{array}{l}\text { - 95\% dos funcionários são do sexo } \\
\text { masculino e o restante (5\%) são do sexo } \\
\text { feminino. } \\
\text { - A faixa etária média dos funcionários está } \\
\text { em torno de } 29 \text { anos. } \\
\text { - Todos os funcionários que trabalham na } \\
\text { parte operacional (produção) possuem no } \\
\text { mínimo o 20 grau completo e os dos } \\
\text { setores administrativos possuem ou estão } \\
\text { matriculados em um curso superior. } \\
\text { - A empresa possui um programa de } \\
\text { subsídio educacional para os trabalhadores } \\
\text { que querem ou estão se aperfeiçoando } \\
\text { através de estudos (graduação, pós- } \\
\text { graduação, curso de línguas, etc). } \\
\text { - Os métodos de recrutamento adotados } \\
\text { pela empresa são: recrutamento interno, } \\
\text { programas de estágios, parceria com } \\
\text { escolas técnicas como o SENAl, divulgação } \\
\text { em universidades e internet. } \\
\text { - Quando um funcionário ingressa na } \\
\text { empresa, ele recebe um treinamento } \\
\text { chamado de integração com duração de } \\
\text { uma semana. Nesse treinamento o } \\
\text { funcionário recebe informações gerais } \\
\text { sobre a empresa, conhece os regulamentos } \\
\text { adotados pela empresa, entre outras }\end{array}$ \\
\hline
\end{tabular}




\begin{tabular}{|c|c|}
\hline & $\begin{array}{l}\text { particularidades. } \\
\text { - O grupo leva suas responsabilidades como } \\
\text { empregador a sério e, além de postos de } \\
\text { trabalho atraentes, oferece uma política de } \\
\text { remuneração baseada no desempenho. } \\
\text { - Na busca por gerar o contínuo } \\
\text { desenvolvimento profissional e convencida } \\
\text { sobre a importância do conhecimento e da } \\
\text { capacitação, foi criada a universidade da } \\
\text { empresa. } \\
\text { - A empresa possui uma preocupação com } \\
\text { questões de segurança e saúde do } \\
\text { trabalhador tanto que a companhia investe } \\
\text { cada vez mais em melhorias para dar } \\
\text { continuidade à sua meta de índice zero em } \\
\text { acidentes de trabalho. Um dos projetos } \\
\text { que ajuda a difundir esta ação é o GATS } \\
\text { (Grupo de Apoio ao Trabalho Seguro). }\end{array}$ \\
\hline Gestão da qualidade & $\begin{array}{l}\text { - Utilização de diversas ferramentas da } \\
\text { qualidade como: PDCA, diagrama de causa } \\
\text { e efeito (Ishikawa), brainstorming, controle } \\
\text { estatístico de processos (CEP), análise de } \\
\text { modo e efeito de falha (FMEA), Seis Sigma, } \\
\text { RCM (Reliability Centered Maintenance - } \\
\text { Manutenção Centrada na Confiabilidade) e } \\
\text { metodologia APQP (Advanded Product } \\
\text { Quality Planning). }\end{array}$ \\
\hline
\end{tabular}

Continuação do Quadro 3 - Ações nas áreas infra-estruturais

\begin{tabular}{|l|l|}
\hline Gestão da qualidade & - A empresa desenvolve diversos projetos \\
para a promoção da qualidade, com \\
ações de conscientização das equipes, \\
treinamento constante e suporte aos \\
fornecedores. Alguns deles são: First in \\
Quality e Desafio TQM (Total Quality \\
Management). \\
- A empresa conta com inúmeras \\
certificações da qualidade como: ISO \\
9001, Q1-Ford, QS 9000, VDA 6.1, entre \\
outras. \\
\hline pistemas de \\
produtos & - O grupo investe 5\% do faturamento \\
& anual de vendas na área de pesquisa e \\
desenvolvimento para fomentar a \\
invenção de novas tecnologias, os \\
registros de diversas patentes e estimular \\
a criatividade em todas as áreas da \\
empresa, sempre acreditando que para a \\
inovação não existem limites. \\
- A equipe de P\&D da planta estudada \\
possui cerca de 20 engenheiros de \\
produto que trabalham no \\
desenvolvimento de novos produtos. \\
- O desenvolvimento de novos produtos e \\
tecnologias é organizado diretamente \\
pelas divisões operacionais e unidades de \\
negócios.
\end{tabular}




\begin{tabular}{|l|l|}
\hline & $\begin{array}{l}\text { - O lançamento de novos produtos no } \\
\text { mercado segue a tendência dos clientes } \\
\text { (montadoras). }\end{array}$ \\
\hline Planejamento e controle da produção & $\begin{array}{l}\text { - O planejamento e controle da produção } \\
\text { (PCP) da empresa é realizado por meio } \\
\text { das previsões de demanda das } \\
\text { montadoras e da rede de oficinas } \\
\text { autorizadas (mercado de reposição). } \\
\text { - Para o PCP é utilizado o software ERP } \\
\text { (Enterprise Resource Planning) da SAP e o } \\
\text { sistema kanban. }\end{array}$ \\
\hline Medição e sistemas de recompensa & $\begin{array}{l}\text { - Aplica o conceito da meritocracia } \\
\text { (premiar os trabalhadores pelo seu } \\
\text { desempenho e resultados alcançados, } \\
\text { levando-os aos postos mais elevados na } \\
\text { hierarquia através de seus próprios } \\
\text { méritos). } \\
\text { - Caso alguma solução proposta por um } \\
\text { funcionário seja adotada, este é } \\
\text { recompensado através de um programa } \\
\text { chamado de Plano de Sugestões, que } \\
\text { paga uma certa quantia de dinheiro. }\end{array}$ \\
\hline
\end{tabular}

Fonte: Elaborado pelos autores

Na próxima seção, é realizada uma análise das relações entre as ações nas áreas de decisão e as prioridades competitivas da empresa.

\section{RELAÇÕES ENTRE AS AÇÕES NAS ÁREAS DE DECISÃO E AS PRIORIDADES COMPETITIVAS}

De todas as ações realizadas nas áreas de decisão, pode-se ressaltar diversas que contribuem para 0 atingimento das prioridades competitivas destacadas pela empresa. No Quadro 4, são mostradas as ações que contribuem para o alcance da prioridade qualidade e a quais áreas de decisão elas pertencem.

Quadro 4 - Ações relacionadas com a prioridade qualidade

\begin{tabular}{|l|l|}
\hline \multicolumn{1}{|c|}{ Ação } & \multicolumn{1}{|c|}{ Ação pertencente à área } \\
\hline $\begin{array}{l}\text { 1-) Um dos critérios utilizados para a } \\
\text { escolha do fornecedor é a qualidade. }\end{array}$ & $\begin{array}{l}\text { Integração vertical/gestão de } \\
\text { suprimentos }\end{array}$ \\
\hline $\begin{array}{l}\text { 2-) Prioriza trabalhar com fornecedores que } \\
\text { possuem a certificação de qualidade ISO } \\
9001: 2000 .\end{array}$ & $\begin{array}{l}\text { Integração vertical/gestão de } \\
\text { suprimentos }\end{array}$ \\
\hline $\begin{array}{l}\text { 3-) O controle de qualidade das } \\
\text { mercadorias fornecidas por terceiros fica } \\
\text { vinculado às normas de inspeção e controle } \\
\text { da qualidade da empresa. }\end{array}$ & $\begin{array}{l}\text { Integração vertical/gestão de } \\
\text { suprimentos }\end{array}$ \\
\hline $\begin{array}{l}\text { 4-) A empresa todos os anos premia os } \\
\text { fornecedores que mais se destacam em } \\
\text { suas atividades e um dos critérios avaliados } \\
\text { é a qualidade. }\end{array}$ & $\begin{array}{l}\text { Integração vertical/gestão de } \\
\text { suprimentos }\end{array}$ \\
\hline $\begin{array}{l}\text { 5-) O entrevistado salienta a importância do } \\
\text { trabalho conjunto com os fornecedores } \\
\text { para o desenvolvimento de projetos, }\end{array}$ & $\begin{array}{l}\text { Integração vertical/gestão de } \\
\text { suprimentos }\end{array}$ \\
\hline
\end{tabular}




\begin{tabular}{|l|l|}
\hline sobretudo com foco na qualidade. & \\
\hline $\begin{array}{l}\text { 6-) Possui atualmente } 30 \% \text { de máquinas } \\
\text { automatizadas. }\end{array}$ & Tecnologia de processo \\
\hline 7-) Criação da universidade da empresa. & Sistemas de recursos humanos \\
\hline $\begin{array}{l}\text { 8-) Utilização de diversas ferramentas da } \\
\text { qualidade. }\end{array}$ & Gestão da qualidade \\
\hline $\begin{array}{l}\text { 9-) A empresa desenvolve diversos projetos } \\
\text { para a promoção da qualidade. }\end{array}$ & Gestão da qualidade \\
\hline $\begin{array}{l}\text { 10-) A empresa conta com inúmeras } \\
\text { certificações da qualidade. }\end{array}$ & Gestão da qualidade \\
\hline
\end{tabular}

Fonte: Elaborado pelos autores

Todas as dez ações do Quadro 4 trazem contribuições para a prioridade qualidade. Por exemplo, a premiação destacada na quarta ação distingue os fornecedores pelos padrões de qualidade e eficiência apresentados no suprimento dos produtos e serviços, fortalecendo assim o relacionamento da empresa com seus melhores parceiros. Já para a sexta ação, a utilização de máquinas automatizadas faz com que haja uma redução dos erros de produção quando estas são comparadas ao uso de máquinas manuais onde vários defeitos ocorrem devido à fadiga do operador.

$\mathrm{Na}$ busca por gerar o contínuo desenvolvimento profissional de seus funcionários e convencida sobre a importância do conhecimento e da capacitação, foi criada a universidade da empresa (sétima ação). E de acordo com o entrevistado, por meio dos cursos e treinamentos oferecidos, foi possível notar uma melhora na qualidade das peças fabricadas pelos colaboradores. Já com relação aos projetos para a promoção da qualidade (ação 9), a empresa desenvolve diversos. Alguns deles são:

- First in Quality: baseado no princípio de zero defeito, busca a redução sustentável dos custos de falhas, seja por garantia, refugo ou retrabalho;

- Desafio TQM: criado para estimular e reconhecer projetos que promovam a melhoria contínua e a inovação das empresas do grupo.

A seguir, no Quadro 5, são mostradas as ações que contribuem para o alcance da prioridade entrega e a quais áreas de decisão elas pertencem.

Quadro 5 - Ações relacionadas com a prioridade entrega

\begin{tabular}{|l|l|}
\hline \multicolumn{1}{|c|}{ Ação } & \multicolumn{1}{|c|}{ Ação pertencente à área } \\
\hline $\begin{array}{l}\text { 1-) Um dos critérios utilizados para a } \\
\text { escolha do fornecedor é a entrega. }\end{array}$ & Integração vertical/gestão de suprimentos \\
\hline $\begin{array}{l}\text { 2-) Possui atualmente 30\% de máquinas } \\
\text { automatizadas. }\end{array}$ & Tecnologia de processo \\
\hline $\begin{array}{l}\text { 3-) A produção da planta estudada opera } \\
\text { através do sistema fazer para estoque } \\
\text { (make to stock). }\end{array}$ & Organização da produção \\
\hline $\begin{array}{l}\text { 4-) O planejamento e controle da } \\
\text { produção (PCP) da empresa é realizado } \\
\text { por meio de previsões de demanda. }\end{array}$ & Planejamento e controle da produção \\
\hline $\begin{array}{l}\text { 5-) Para o PCP é utilizado o ERP e o } \\
\text { sistema kanban }\end{array}$ & Planejamento e controle da produção \\
\hline
\end{tabular}

Fonte: Elaborado pelos autores 
Todas as cinco ações do Quadro 5 trazem contribuições para a prioridade entrega. Para a primeira ação, a empresa estudada busca trabalhar com fornecedores que façam entregas de peças (matéria-prima) nas quantidades corretas e na data prometida para que surpresas não ocorram e não prejudiquem as entregas dos produtos finais aos clientes. $\mathrm{O}$ uso de máquinas automatizadas (ação 2) faz com que o processo produtivo fique mais ágil por meio da redução do lead time de produção, possibilitando assim entregas mais rápidas. Já o sistema make to stock (ação 3) é adequado para entregas imediatas, pois o produto já se encontra disponível no estoque. Para a quarta ação, é de conhecimento que o uso de técnicas de previsão permitem a redução das incertezas de vendas futuras, evitando assim os atrasos nas entregas. E por fim, a utilização dos sistemas ERP (Enterprise Resource Planning) e kanban (ação 5) permitem uma melhor comunição entre os diversos setores, proporcionando agilidade nas tomadas de decisões e beneficiando desta forma a prioridade em questão.

A seguir, no Quadro 6, são mostradas as ações que contribuem para o alcance da prioridade custo e a quais áreas de decisão elas pertencem.

Quadro 6 - Ações relacionadas com a prioridade custo

\begin{tabular}{|l|l|}
\hline \multicolumn{1}{|c|}{ Ação } & \multicolumn{1}{|c|}{ Ação pertencente à área } \\
\hline $\begin{array}{l}\text { 1-) Possui atualmente 30\% de máquinas } \\
\text { automatizadas. }\end{array}$ & Tecnologia de processo \\
\hline $\begin{array}{l}\text { 2-) A empresa oferece uma política de } \\
\text { remuneração baseada no desempenho. }\end{array}$ & Sistemas de recursos humanos \\
\hline $\begin{array}{l}\text { 3-) A empresa possui uma preocupação } \\
\text { com questões de segurança e saúde do } \\
\text { trabalhador e tem como meta zero } \\
\text { acidentes de trabalho. }\end{array}$ & Sistemas de recursos humanos \\
\hline $\begin{array}{l}\text { 4-) Utilização de diversas ferramentas da } \\
\text { qualidade. }\end{array}$ & Gestão da qualidade \\
\hline
\end{tabular}

Fonte: Elaborado pelos autores

Todas as quatro ações do Quadro 6 trazem contribuições para a prioridade custo. Para a primeira ação, por meio do uso de máquinas automatizadas, o volume de produção aumenta e consequentemente o custo unitário do produto diminui. A política de remuneração baseada no desempenho (ação 2) possui como um dos critérios de avaliação o item produtividade. E com este incentivo, os operadores buscam sempre o aumento de produtividade e este aumento acarreta na redução do custo unitário do produto, assim como acontece na ação 1. A terceira ação mostra a preocupação da empresa com as questões de segurança e saúde do trabalhador. De acordo com o entrevistado, a mobilização em torno da segurança e da saúde se expressa em atitudes coletivas e individuais, que fazem a diferença e otimizam os resultados. Um dos projetos que ajuda a difundir esta ação é o GATS (Grupo de Apoio ao Trabalho Seguro) que foi criado para atuar na prevenção de acidentes e dar suporte à gestão integrada de saúde, segurança e meio ambiente. Esta ação faz com que gere benefícios para o custo da mão de obra, pois reduz os afastamentos, aposentadorias por invalidez, etc. Já a utilização de diversas ferramentas da qualidade (ação 4) como: PDCA, diagrama de causa e efeito (Ishikawa), brainstorming, controle estatístico de processos (CEP), análise de modo e efeito de falha (FMEA), Seis Sigma, RCM 
(Reliability Centered Maintenance - Manutenção Centrada na Confiabilidade) e metodologia APQP (Advanded Product Quality Planning), impactam no custo, pois reduzem de forma substancial o número de retrabalhos e refugos de peças.

Para a prioridade serviço (apoio ao cliente), nenhuma ação foi identificada durante a realização do estudo que pudesse trazer alguma contribuição.

A seguir, no Quadro 7, são mostradas as ações que contribuem para o alcance da prioridade flexibilidade e a quais áreas de decisão elas pertencem.

Quadro 7 - Ações relacionadas com a prioridade flexibilidade

\begin{tabular}{|l|l|}
\hline \multicolumn{1}{|c|}{ Ação } & \multicolumn{1}{|c|}{ Ação pertencente à área } \\
\hline $\begin{array}{l}\text { 1-) Possui atualmente 30\% de máquinas } \\
\text { automatizadas. }\end{array}$ & Tecnologia de processo \\
\hline $\begin{array}{l}\text { 2-) O arranjo físico (layout) presente é o } \\
\text { arranjo celular para todas as operações. }\end{array}$ & Organização da produção \\
\hline $\begin{array}{l}\text { 3-) O grupo investe 5\% do faturamento } \\
\text { anual de vendas na área de pesquisa e } \\
\text { desenvolvimento. }\end{array}$ & $\begin{array}{l}\text { Sistemas de } \\
\text { desenvolvimento de } \\
\text { novos produtos }\end{array}$ \\
\hline
\end{tabular}

Fonte: Elaborado pelos autores

Todas as três ações do Quadro 7 trazem contribuições para a prioridade flexibilidade. Para a primeira ação, o uso de máquinas automatizadas proporciona a redução do lead time de produção quando comparado ao uso de máquinas manuais. Desta forma é possível realizar a alternância do volume e mix (variedade) de peças com mais facilidade. A utilização do arranjo físico celular (ação 2), possibilita também uma maior facilidade em se trabalhar com flexibilidades de volume e mix. E a última ação nos mostra a preocupação da empresa com a área de pesquisa e desenvolvimento, isto é, ela valoriza a flexibilidade de produto, que é a habilidade de a operação introduzir novos produtos no mercado.

\section{CONSIDERAÇÕES FINAIS}

Este estudo teve por objetivo analisar a estratégia de produção de uma indústria fabricante de peças para automóveis. E para realizá-lo foi utilizado o método do estudo de caso desenvolvido por meio de entrevistas semiestruturadas, observação direta com visitas ao setor de produção e consulta a fontes de dados secundárias.

As questões de pesquisa (propostas na seção Introdução) que nortearam o desenvolvimento deste trabalho e que, portanto, procurou-se responder foram as seguintes:

Questão 1-) Quais são as prioridades competitivas destacadas pela empresa com o intuito de satisfazer seu mercado consumidor?

Questão 2-) Quais são as ações realizadas nas áreas de decisão estruturais e infraestruturais?

Questão 3-) Destas ações nas áreas de decisão, quais contribuem para o alcance das prioridades competitivas destacadas pela empresa? 
Ao analisar a seção "Prioridades Competitivas", viu-se que de acordo com o engenheiro da área de produção, a empresa dá destaque principalmente para as prioridades competitivas qualidade e entrega para satisfazer seu mercado consumidor. A qualidade é priorizada por meio da avaliação das necessidades dos clientes e, em função destas são definidos os requisitos de qualidade do produto. Já a prioridade entrega também recebe um destaque especial, pois ainda de acordo com o entrevistado, é importante que os itens dos clientes sejam entregues nas quantidades certas e na data prometida. Custo, serviço e flexibilidade são prioridades também valorizadas pela empresa, mas com um grau de importância menor.

Com relação à questão 2, as ações realizadas nas áreas de decisão foram expostas na seção "Áreas de Decisão Estruturais e Infra-estruturais". Por exemplo, para a área estrutural tecnologia de processo, a empresa possui $30 \%$ de máquinas automatizadas; faz todo o projeto e desenvolvimento de um novo processo em conjunto com os fornecedores de equipamentos, dispositivos, conhecimento etc.

No que diz respeito à área infra-estrutural gestão da qualidade, ela utiliza diversas ferramentas da qualidade como: PDCA, diagrama de causa e efeito (Ishikawa), brainstorming, controle estatístico de processos (CEP), análise de modo e efeito de falha (FMEA), Seis Sigma, RCM (Reliability Centered Maintenance - Manutenção Centrada na Confiabilidade) e metodologia APQP (Advanded Product Quality Planning); conta com inúmeras certificações da qualidade como: ISO 9001, Q1-Ford, QS 9000, VDA 6.1, entre outras.

Já a área planejamento e controle da produção (PCP) faz uso de previsões de demanda das montadoras e da rede de oficinas autorizadas (mercado de reposição); utiliza o sistema kanban etc. Entre outras ações desenvolvidas nas diversas áreas de decisão.

Das ações realizadas nas áreas de decisão, diversas contribuem para o alcance das prioridades competitivas destacadas pela empresa (questão 3). Por exemplo, para a prioridade qualidade, as ações como trabalhar com fornecedores que possuem a certificação de qualidade ISO 9001:2000; premiação aos fornecedores que mais se destacam em suas atividades sendo um dos critérios avaliados o quesito qualidade; utilização de ferramentas da qualidade etc, contribuem para o seu alcance.

Já para a prioridade entrega, as ações como operar a produção da planta através do sistema fazer para estoque (make to stock); utilizar previsões de demanda e sistema kanban para desenvolver o PCP, entre outras, contribuem para o atingimento da prioridade em questão.

Diversas ações também trouxeram contribuições para as prioridades custo e flexibilidade. Já para a prioridade serviço nenhuma ação foi relacionada.

Após as três questões serem respondidas, conseguiu-se verificar: (1) as prioridades competitivas destacadas pela empresa, (2) as ações realizadas nas áreas de decisão estruturais e infra-estruturais e (3) as ações nas áreas de decisão que contribuem para o alcance das prioridades competitivas da fábrica estudada. 


\title{
Production strategy of an automotive parts manufacturing company
}

\begin{abstract}
The intense technological development in the last decades, mainly due to the microelectronics, the intensification of trade between countries, the global supply used by large corporations, among other aspects, have made competition in the different markets more and more fierce. In this scenario, the strategic approach to production management is critical for companies to remain competitive. This study aimed to identify and analyze the production strategy of a company that manufactures parts for automobiles. The research method used was the case study, conducted through interviews, direct observation and consultation of secondary data sources. As a result it was possible to verify: the competitive priorities highlighted by the company, being quality and delivery considered the most important; the actions carried out in the various structural and infrastructural decision areas; and actions in decision areas that contribute to the achievement of the competitive priorities of the factory studied. In order to improve the quality priority, we highlight the work performed with its suppliers, such as the ISO 9001: 2000 quality certification requirement; awards to the suppliers that stand out most in their activities; use of quality tools etc. As for delivery priority, actions aimed at the development of the PCP (planning and production control), among others, have contributed significantly to the performance required in the priority in question.
\end{abstract}

KEYWORDS: Production Strategy. Competitive Priorities. Structural Decision Areas. Infrastructure Decision Areas. Auto Parts Industry. 
ALVES FILHO, A.G.; NOGUEIRA, E.; BENTO, P.E.G. Análise das estratégias de produção de seis montadoras de motores para automóveis. Revista Gestão e Produção, São Carlos, v.18, n.3, p.603-618, 2011. crossref

AMOAKO-GYAMPAH, K.; ACQUAAH, M. Manufacturing strategy, competitive strategy and firm performance: an empirical study in a developing economy environment. International Journal of Production Economics, v. 111, 2008. crossref

ANSOFF, H.; McDONNEL, E. Implantando a administração estratégica. 2. ed. São Paulo: Atlas, 2009.

BERTO, R.M.V.S.; NAKANO, D.N. A produção científica nos anais do encontro nacional de engenharia de produção: um levantamento dos métodos e tipos de pesquisa. Revista Produção, v.9, n.2, p. 65-75, 2000. crossref

BRITO DE OLIVEIRA, L.G. Relação entre prioridades competitivas e estrutura organizacional: estudo multicasos em empresas do setor de autopeças de Sorocaba/SP. 2017. Dissertação (Mestrado) - Programa de Pós-Graduação em Engenharia de Produção, Universidade Federal de São Carlos, Campus Sorocaba, 2017.

CALIFE, N.F.S.; NOGUEIRA, E.; ALVES FILHO, A.G. Empresas do setor de linha branca e suas estratégias competitivas e de produção. Revista Produção on Line, v. 10 , n. 2, p. $274-296,2010$. cross ref

DAVIS. M.; AQUILANO, N.; CHASE, R. Fundamentos da administração da produção. Porto Alegre: Bookman, 2001.

DÍAZ-GARRIDO, E.; MARTÍN-PEÑA, M.; SANCHEZ-LÓPEZ, J. Competitive priorities in operations: development of an indicator of strategic position. CIRP Journal of Manufacturing Science and Technology, New York, v. 4, 2011. crossref

FINE, C. H.; HAX, A. C. Manufacturing strategy: a methodology and an illustration. Interface, v.15, n.6, p.28-46, 1985. crossref

GALEAZZO, A.; KLASSENB, R.D. Organizational context and the implementation of environmental and social practices: what are the linkages to manufacturing strategy? Journal of Cleaner Production, v. 108, 2015. crossref 
GARVIN, D.A. Manufacturing strategic planning. California management Review, summer 1993. crossref

GIL, A.C. Como elaborar projetos de pesquisa. 3a ed. São Paulo: Atlas, 1991.

GODOY, A.S. Introdução à pesquisa qualitativa e suas possibilidades. Revista de Administração de Empresas, São Paulo, v.35, n.2, p.57-63, 1995.

GÖLEÇ, A. A relationship framework and application in between strategy and operational plans for manufacturing industry. Computers \& Industrial Engineering, v. 86, 2015. crossref

GUIMARÃES, M.R.N.; FILHO, A.M.T.; LARA, F.F.; SALTORATO, P. Estratégia de produção na indústria de autopeças: estudo multicasos em empresas da região de Sorocaba. Revista Produção on Line, v. 14, n. 2, p. 499-532, 2014. crossref

GUPTA, Y.P.; LONIAL, S.C. Exploring linkages between manufacturing strategy, business strategy and organizational strategy. Production and Operations Management, v. 7, n. 3, 1998. crossref

HAYES, R.; WHEELWRIGHT, S.C. Restoring our competitive edge: competing through manufacturing. John Willey \& Sons, 1984.

HAYES, R.; WHEELWRIGHT, S. C.; CLARK, K. B. Dynamic manufacturing: creating the learning organization. New York: The Free Press, 1988.

HAYES, R.; PISANO, G. Beyond world-class: the new manufacturing strategy. Harvard Business Review, Boston, v. 72, n. 1, 1994.

HAYES, R.; PISANO, G.; UPTON, D.; WHEELWRIGHT, S. Produção, estratégia e tecnologia: em busca da vantagem competitiva. Porto Alegre: Ed. Bookman, 2008.

HILL, T. Manufacturing strategy. London: Mc Graw-Hill, 1989.

KROES, J.R.; GHOSH, S. Outsourcing congruence with competitive priorities: impact on supply chain and firm performance. Journal of Operations Management, v. 28, 2010. crossref 
LARA, F.F. Prioridades competitivas e inovação em pequenas empresas do setor metal mecânico: um estudo multicasos na região de Sorocaba. 2013. Dissertação (Mestrado) - Programa de Pós-Graduação em Engenharia de Produção, Universidade Federal de São Carlos, Campus Sorocaba, 2013.

LUZZINI, D.; CANIATO, F.; RONCHI, S.; SPINA, G. A transaction costs approach to purchasing portfolio management. International Journal of Operations \& Production Management, v. 32, 2012. crossref

MARTINS, G.A.; THEÓPHILO, C.R. Metodologia da investigação científica para ciências sociais aplicadas. 2.ed. São Paulo: Atlas, 2009.

MILLS, J.; PLATTS, K.; GREGORY, M. A framework for the design of manufacturing strategy processes: a contingency approach. International Journal of Operations and Production Management, v. 15, n. 4, p. 17-49, 1995. crossref

MINTZBERG, H.; QUINN, J.B. The strategy process: concepts, contexts, cases. EUA: Prentice Hall, 1991.

MINTZBERG, H.; AHLSTRAND, B.; LAMPEL, J. Safári da estratégia: um roteiro pela selva do planejamento estratégico. 2a ed. Porto Alegre: Bookman, 2010.

NAIR, A.; BOULTON, W.R. Innovation-oriented operations strategy typology and stage based model. International Journal of Operations \& Production Management, v. 28, n. 8, 2008. crossref

NOGUEIRA, E. Empresas fabricantes de revestimentos cerâmicos e a gestão de seus sistemas produtivos: proposição de um modelo. 2002. Tese (Doutorado) FGV - Escola de Administração de Empresas de São Paulo, São Paulo, 2002.

PIRES, S. R. I. Integração do planejamento e controle da produção a uma estratégia de manufatura. 1994. Tese (Doutorado) - Escola de Engenharia de São Carlos, USP, São Carlos, SP, 1994.

PORTER. M. E. Estratégia competitiva: técnicas para análise de indústria e da concorrência. Rio de Janeiro: Campus, 1986.

PORTER, M. What is strategy? Harvard Business Review, 1996.

RITZMAN, L.; KRAJEWSKI, L.J. Administração da produção e operações. São

Paulo: Prentice Hall, 2003. 
SANTOS, L.; GOHR, C.; VARVAKIS, G. Um método para identificação e análise de competências e recursos estratégicos das operações de serviços. Gestão \& Produção, São Carlos, v. 18, n. 4, 2011. crossref

SKINNER, W. Manufacturing - missing link in corporate strategy. Harvard Business Review, v.47, n.3, p.136-145, 1969.

SLACK, N. et al. Administração da produção. 2 ed. São Paulo: Atlas. 2002.

SUN, H.; HONG, C. The alignment between manufacturing and business strategies: its influence on business performance. Technovation, v. 22, 2002. crossref

SWAMIDASS, P.M. Manufacturing strategy: its assessment and practice. Journal of Operation Management, v.6, n. 4, 1986. crossref

VOSS, C. Alternative paradigms for manufacturing strategy. International Journal of Operations \& Production Management, v. 15, n.4, 1995. crossref

WARD, P.; DURAY, R. Manufacturing strategy in context: environment, competitive strategy and manufacturing strategy. Journal of Operations Management, v. 18, 2000. crossref

WHEELWRIGHT, S.C. Manufacturing strategy: defining the missing link. Strategic Management Journal, v.5, p.77-91, 1984. crossref 
Recebido: 29 Jun. 2019

Aprovado: 09 Out. 2020

DOI: 10.3895/gi.v16n1.10306

Como citar:

LAZARIN, D.F. et al. Modelo para a formatação dos artigos a serem submetidos à Revista Gestão Industrial

R. Gest. Industr. Ponta Grossa, v. 16, n. 1, p. 121-144, Jan./Mar. 2020. Disponível em:

https://periodicos.utfpr.edu.br/revistagi.

Correspondência:

Daniel França Lazarin

Avenida 23, número 1981, Bairro Centro, Ituiutaba, MG, Brasil.

Direito autoral: Este artigo está licenciado sob os termos da Licença Creative Commons-Atribuição 4.0 Internacional.

\section{(c) (1)}

